\title{
Co-infection Dynamics of Canine Parasitic Diseases In Osun State, Nigeria: A Retrospective Approach
}

\author{
Ola-Fadunsin S. D.*, Hussain K., Rabiu M., Ganiyu I. A. \\ Department of Veterinary Parasitology and Entomology, Faculty of Veterinary Medicine, \\ University of Ilorin, PMB 1515, Ilorin, Kwara State, Nigeria. \\ Accepted January, 2019 and Published February, 2019
}

\begin{abstract}
Multiple parasitic co-infections are a normal occurrence in animals. A ten year (2006-2015) data of parasitic diseases diagnosed in the major Veterinary clinics in Osun state was collected and subjected to statistical analysis. The prevalence of parasitic diseases co-infection, the epidemiological risk factors and the Spearman's correlation coefficient associated with parasitic diseases co-infection was carried out to determine the dynamics of canine parasitic diseases in Osun State. A significant number of dogs were diagnosed with two or more parasitic infections at the same time. Exotic breed of dogs recorded a significant $(P<0.05)$ lower prevalence of parasitic disease co-infections compared to indigenous and cross breeds. Young dogs were more prone to multiple parasite co-infections compared to growing and adult dogs. There was no significant difference $(P>0.05)$ within gender as it pertains to multiple parasitic diseases co-infection. Higher number of parasite co-infections was recorded during the wet season than the dry season. There was a positive correlation between the occurrence of tick infestation with babesiosis, and tick infestation with ehrlichiosis. There is need for an improved Veterinary medical attention and hygienic practices given to dogs in the study area as multiple parasitic diseases co-infection could cause severe and adverse effect on the health, reproduction and performance of dogs.
\end{abstract}

Keywords: Canine parasitic conditions; Co-infections; Epidemiology; Osun State; Veterinary

*Corresponding author:

E-mail: olashodam2@yahoo.com

Tel: +2349060054605 


\section{INTRODUCTION}

Co-infection also known as polyparasitism, is the simultaneous infections with more than one parasite species in an individual host [1], or during a sequential infection as well as when interactions among parasite species facilitate co-occurrence [2]. This condition is very common in animals [3] and can have important repercussions on animal health because it can alter host susceptibility to other parasites, infection duration, transmission risks and dynamics, clinical symptoms and consequently treatment and prevention strategies [2], as treatment of one species could result in changes in another parasite not directly targeted by the treatment [4]. Within a host, the co-infecting parasites may not always act independently of each other, and may interact, modifying the densities of each other and their impact on the infected host as opposed to when they exist as single infection [5], or antagonistic, i.e. the presence of one parasite may inhibit subsequent infections by other parasites [2].

Dogs (Canis lupus familiaris) are the most successful canids that are of close association to human worldwide. They have contributed to the physical, social and emotional well-being of their owners, particularly children [6]. Recent genetic fossil and DNA studies confirm that dogs were early as over 100,000 years ago [7].

Parasitism on dogs is harmful and poses serious health challenges, such as reduced growth rate, generalized ill health, lowered resistance to infectious disease, reduced work efficiency and even death [8]. A variety of parasites have been reported to infect dogs in Nigeria. Omudu et al. [9] documented the infestation of ticks, lice and fleas in their study conducted in Markurdi, Okubanjo et al. [10] reported the presence of Babesia canis and Hepatozoon canis in Zaria, Sowemimo and Ayanniyi [11] documented the infection with gastrointestinal parasites in their study carried out in Ilesha. It is an established fact that Nigerian dogs are been plagued by different parasitic conditions, but to the best of our knowledge no study has been carried out to show the dynamics of multiple parasitic conditions in Nigerian dogs. The purpose of the present study was to determine the dynamics of multiple parasitic conditions in dogs in Osun State using Veterinary clinical records.

\section{MATERIALSAND METHODS}

\section{Study area}

This study was conducted in Osun State which covers an area of 9,026 square kilometers and is located between latitude $7^{\circ} 30^{\prime} \mathrm{N}$ and longitude $4^{\circ} 30^{\circ} \mathrm{E}$. Its climate is characterized by a tropical wet season (March, April, May, June, July, September and October) and the dry season (November, December, January, February and August) with a lowland tropical rain forest vegetation. The state records a mean annual rainfall of between $127.8 \mathrm{~cm}$ and 159.8 $\mathrm{cm}$ and an average annual temperature ranging from $21.1{ }^{\circ} \mathrm{C}$ to $31.9^{\circ} \mathrm{C}$. It records a mean relative humidity of between $58.7 \%$ and $79.7 \%$ $[12,13]$.

\section{Data Collection}

Clinical records of all diagnosed and confirmed cases of parasitic diseases of dogs presented to the major state Veterinary clinics located in Osogbo, Ilesa, Ede and Ikirun from January 2006-December 2015 was collected. The records included all the animal information such as breed, age and gender as well as the date of presentation to the clinic. Diagnosis of each disease was carried out in the clinic based on case history, physical examination and clinical signs. Cases were confirmed in the laboratory by blood and faecal examination using a light microscope, ectoparasite examination using a stereomicroscope. Labouratory procedures were carried out as described by Soulsby [14]. Faecal samples were examined using the simple floatation technique. Briefly, about 1gram of 
faeces was emulsified in flotation solution (saturated $\mathrm{NaCl}$ ) using a spatula and the solution was strain through a tea sieve into a test tube (in a holder) until a meniscus was formed at the mouth of the test tube. A coverslip was carefully placed over the meniscus, and allowed to stand for 20/mins. Afterwards, the coverslip was then placed on a glass slide and examined at x10 and x40 magnification of the microscope. The blood samples were examined using the direct wet blood mounts and the thin blood smear techniques. Briefly, two drops of the fresh blood was placed in the middle of a clean grease-free glass slide and covered with a cover slip. It was then viewed with a light microscope at $\mathrm{x} 10$ objective magnification for motile parasites (direct wet blood mounts). For the thin blood smear, a drop of blood was placed at one end of a grease-free glass slide with the aid of a micropipette. A spreader was used to make contact with the blood at an angle of about $45^{\circ}$ and then pushed forward smoothly through the length of the glass slide forming a mono layer of blood cells on the glass slide, and allowed to air-dry. It was then fixed with $100 \%$ methanol for $5 \mathrm{~min}$ and then stained with Giemsa for 25-30 min. The slide was viewed at x100 magnification of the microscope with oil immersion. Morphological keys as described by Soulsby [14], was used as a guide for all parasites. The Clinical and microscopic examinations, and records about each dog were carried out by qualified veterinarians and laboratory scientist.

\section{Data computation and Statistical analysis}

The retrieved data were entered in to Microsoft Excel (2010) and worked upon therein. Statistical evaluation was carried out using the Chi-square $(\chi 2)$ test to measure for significant association at $P<0.05$. Spearman's correlation was used to measure the strength of association for each parasitic disease co-infection with $P<0.05$ considered as the level of significance. The strength of association between parasitic conditions co-infection was measured as described by Mukaka [15]. All statistical tests were conducted using statistical package for social sciences (SPSS) version 22 (SPSS Inc., Chicago).

\section{RESULTS}

Of the 2820 dogs diagnosed with parasitic diseases, $1684(59.72 \%, 95 \% \mathrm{CI}=57.90 ; 61.52)$ were diagnosed with single infection. Helminthosis was the most prevalent sole infection $(1299,46.06 \%, 95 \% \mathrm{CI}=44.23$; 47.91), while flea infestation and ehrlichiosis were the least prevalent sole infection with each recording 2 cases $(0.07 \%, 95 \% \mathrm{CI}=0.01 ; 0.23)$ (Table 1).

Eight hundred and one dogs were diagnosed with double parasitic infection representing $28.40 \%$ of the total dog population. Helminthosis + ticks infection, and babesiosis + ticks infection were the double parasitic disease conditions that were more than 280 in number, while lice infestation + mange, helminthosis + flea infestation, ticks infestation + flea infestation, helminthosis + babesiosis, ticks infestation + myiasis, mange + ehrlichiosis, and babesiosis + mange had counts less than 10 . Of the $305(10.82 \%)$ dogs diagnosed with three parasitic disease conditions concurrently, helminthosis + babesiosis + ticks infestation $(210,7.45 \%)$ was the most prevalent, while helminthosis + ticks infestation + ehrlichiosis, helminthosis + ticks infestation + trypanosomosis, helminthosis + lice infestation + ehrlichiosis, and lice infestation + mange + flea infestation were the least prevalent recording a case $(0.04 \%)$ each (Tables 2 and 3 ).

The prevalence of four parasitic diseases coinfection among dogs in Osun State (20062015) is presented in Table 4 . Twenty seven dogs $(0.96 \%, 95 \% \mathrm{CI}=0.64 ; 1.37)$ were diagnosed with four parasitic disease conditions 
at the same time, with helminthosis + babesiosis + ticks infestation + mange, and helminthosis + ticks infestation + lice infestation + ehrlichiosis been the most numerous combination in the category. Helminthosis + babesiosis + ticks infestation + myiasis was the least prevalent combination in the category.

Three dogs $(0.11 \%, 95 \% \mathrm{CI}=0.03 ; 0.29)$ were diagnosed with five parasitic disease conditions concurrently. Two $(0.07 \%)$ with helminthosis + babesiosis + ticks infestation + lice infestation + flea infestation and one $(0.04 \%)$ with helminthosis + babesiosis + ticks infestation + lice infestation + trypanosomosis (Table 5).

Analysis of the epidemiological factors associated with parasitic diseases co-infection among dogs in Osun State (2006-2015) (Table $6)$ revealed a significant difference $(P<0.05)$ in the exotic and indigenous breeds of dogs diagnosed with the different categories of parasitic disease sole infection and coinfections. There was a significant difference $(P<0.05)$ in the number of cross breed of dogs that were diagnosed with one, two, three and four parasitic disease conditions. Within breeds, the cross breed had a significantly $(P<0.05)$ higher prevalence of single parasitic disease condition compared to the exotic and the indigenous breeds. The exotic and the indigenous breeds had a significantly $(P<0.05)$ higher prevalence of double and triple parasitic disease conditions compared to the cross breed. There was no significant difference $(P>0.05)$ between breeds as it pertains to the prevalence of four parasitic diseases co-infection, while exotic breed of dogs recorded a significantly lower prevalence of five parasitic diseases coinfection compared to the cross and indigenous breeds.

Table 1. Prevalence of single parasitic disease infection among dogs in Osun State (2006-2015).

\begin{tabular}{lll}
\hline Parasitic Disease & Number Positive (\%) & $\mathbf{9 5 \%}$ CI \\
\hline Helminthosis & $1299(46.06)$ & $44.23 ; 47.91$ \\
Babesiosis & $8(0.28)$ & $0.13 ; 0.54$ \\
Ticks Infestation & $208(7.38)$ & $6.45 ; 8.39$ \\
Myiasis & $20(0.71)$ & $0.45 ; 1.07$ \\
Lice Infestation & $30(1.06)$ & $0.73 ; 1.50$ \\
Mange & $109(3.87)$ & $3.20 ; 4.63$ \\
Ehrlichiosis & $2(0.07)$ & $0.01 ; 0.23$ \\
Flea Infestation & $2(0.07)$ & $0.01 ; 0.23$ \\
Trypanosomosis & $6(0.21)$ & $0.09 ; 0.44$ \\
\hline Total & $\mathbf{1 6 8 4}(\mathbf{5 9 . 7 2})$ & $\mathbf{5 7 . 9 0 ; 6 1 . 5 2}$ \\
\hline
\end{tabular}


Table 2. Prevalence of two parasitic diseases co-infection among dogs in Osun State (2006-2015).

\begin{tabular}{lll}
\hline Parasitic Diseases & Number Positive (\%) & $\mathbf{9 5 \%}$ CI \\
\hline Helminthosis + Babesiosis & $2(0.07)$ & $0.01 ; 0.23$ \\
Helminthosis + Ticks Infestation & $303(10.74)$ & $9.64 ; 11.93$ \\
Helminthosis + Myiasis & $13(0.46)$ & $0.26 ; 0.77$ \\
Helminthosis + Lice Infestation & $26(0.92)$ & $0.62 ; 1.33$ \\
Helminthosis + Mange & $82(2.91)$ & $2.33 ; 3.58$ \\
Helminthosis + Flea Infestation & $5(0.18)$ & $0.06 ; 0.39$ \\
Babesiosis + Ticks Infestation & $288(10.21)$ & $9.14 ; 11.37$ \\
Babesiosis + Mange & $1(0.04)$ & $0.002 ; 0.17$ \\
Ticks Infestation + Myiasis & $2(0.07)$ & $0.01 ; 0.23$ \\
Ticks Infestation + Lice Infestation & $38(1.35)$ & $0.97 ; 1.83$ \\
Ticks Infestation + Mange & $11(0.39)$ & $0.21 ; 0.68$ \\
Ticks Infestation + Ehrlichiosis & $16(0.57)$ & $0.34 ; 0.90$ \\
Ticks Infestation + Flea Infestation & $3(0.11)$ & $0.03 ; 0.29$ \\
Lice Infestation + Mange & $9(0.32)$ & $0.16 ; 0.58$ \\
Mange + Ehrlichiosis & $2(0.07)$ & $0.01 ; 0.23$ \\
\hline Total & $\mathbf{8 0 1}(\mathbf{2 8 . 4 0})$ & $\mathbf{2 6 . 7 6 ; 3 0 . 0 9}$ \\
\hline
\end{tabular}

Table 3. Prevalence of three parasitic diseases co-infection among dogs in Osun State (2006-2015).

\begin{tabular}{lll}
\hline Parasitic Diseases & Number Positive (\%) & $95 \%$ CI \\
\hline Helminthosis + Babesiosis + Ticks Infestation & $210(7.45)$ & $6.52 ; 8.46$ \\
Helminthosis + Ticks Infestation + Lice Infestation & $37(1.31)$ & $0.94 ; 1.79$ \\
Helminthosis + Ticks Infestation + Mange & $10(0.35)$ & $0.18 ; 0.63$ \\
Helminthosis + Ticks Infestation + Ehrlichiosis & $1(0.04)$ & $0.002 ; 0.17$ \\
Helminthosis + Ticks Infestation + Flea Infestation & $2(0.07)$ & $0.01 ; 0.23$ \\
Helminthosis + Ticks Infestation + Trypanosomosis & $1(0.04)$ & $0.002 ; 0.17$ \\
Helminthosis + Lice Infestation + Mange & $5(0.18)$ & $0.06 ; 0.39$ \\
Helminthosis + Lice Infestation + Ehrlichiosis & $1(0.04)$ & $0.002 ; 0.17$ \\
Helminthosis + Lice Infestation + Flea Infestation & $2(0.07)$ & $0.01 ; 0.23$ \\
Helminthosis + Mange + Flea Infestation & $2(0.07)$ & $0.01 ; 0.23$ \\
& & \\
\hline
\end{tabular}




$\begin{array}{lll}\text { Babesiosis + Ticks Infestation + Lice Infestation } & 6(0.21) & 0.09 ; 0.44 \\ \text { Babesiosis + Ticks Infestation + Mange } & 11(0.39) & 0.21 ; 0.68 \\ \text { Babesiosis + Ticks Infestation + Ehrlichiosis } & 6(0.21) & 0.09 ; 0.44 \\ \text { Babesiosis + Ticks Infestation + Flea Infestation } & 3(0.11) & 0.03 ; 0.29 \\ \text { Ticks Infestation + Lice Infestation + Mange } & 3(0.11) & 0.03 ; 0.29 \\ \text { Ticks Infestation + Lice Infestation + Flea Infestation } & 2(0.07) & 0.01 ; 0.23 \\ \text { Ticks Infestation + Mange + Ehrlichiosis } & 2(0.07) & 0.01 ; 0.23 \\ \text { Lice Infestation + Mange + Flea Infestation } & 1(0.04) & 0.002 ; 0.17\end{array}$

Table 4. Prevalence of four parasitic diseasesco-infection among dogs in Osun State (2006-2015).

\begin{tabular}{llc}
\hline Parasitic Diseases & Number Positive (\%) & $\mathbf{9 5 \%}$ CI \\
\hline Helminthosis + Babesiosis + Ticks Infestation + Myiasis & $1(0.04)$ & $0.002 ; 0.17$ \\
$\begin{array}{l}\text { Helminthosis + Babesiosis + Ticks Infestation + Lice } \\
\text { Infestation }\end{array}$ & $3(0.11)$ & $0.03 ; 0.29$ \\
$\begin{array}{l}\text { Helminthosis + Babesiosis + Ticks Infestation + Mange } \\
\text { Helminthosis + Babesiosis + Ticks Infestation + }\end{array}$ & $2(0.24)$ & $0.11 ; 0.49$ \\
$\begin{array}{l}\text { Ehrlichiosis } \\
\text { Helminthosis + Babesiosis + Ticks Infestation + }\end{array}$ & $3(0.11)$ & $0.01 ; 0.23$ \\
Trypanosomosis & & $0.03 ; 0.29$ \\
$\begin{array}{l}\text { Helminthosis + Ticks Infestation + Lice Infestation + } \\
\text { Mange }\end{array}$ & $2(0.07)$ & $0.01 ; 0.23$ \\
$\begin{array}{l}\text { Helminthosis + Ticks Infestation + Lice Infestation + } \\
\text { Ehrlichiosis }\end{array}$ & $7(0.24)$ & \\
Babesiosis + Ticks Infestation + Mange + Ehrlichiosis & $2(0.07)$ & $0.11 ; 0.49$ \\
\hline Total & $\mathbf{2 7 ( 0 . 9 6 )}$ & $\mathbf{0 . 6 4 ; 1 . 3 7}$ \\
\hline
\end{tabular}


Table 5. Prevalence of five parasitic diseases co-infection among dogs in Osun State (2006-2015).

\begin{tabular}{llc}
\hline Parasitic Diseases & Number Positive (\%) & 95\% CI \\
\hline $\begin{array}{l}\text { Helminthosis + Babesiosis + Ticks Infestation + Lice } \\
\text { Infestation + Flea Infestation }\end{array}$ & $2(0.07)$ & $0.01 ; 0.23$ \\
$\begin{array}{l}\text { Helminthosis + Babesiosis + Ticks Infestation + Lice } \\
\text { Infestation + Trypanosomosis }\end{array}$ & $1(0.04)$ & $0.002 ; 0.17$ \\
\hline Total & $\mathbf{3 ( 0 . 1 1 )}$ & $\mathbf{0 . 0 3 ; 0 . 2 9}$ \\
\hline
\end{tabular}

Table 6. Epidemiological factors associated with parasitic diseases co-infection among dogs in Osun State (2006-2015).

\begin{tabular}{|c|c|c|c|c|c|c|}
\hline \multirow[t]{2}{*}{ Factors } & \multirow[t]{2}{*}{$\mathbf{N}$} & \multicolumn{5}{|c|}{ Number of Parasitic Diseases (\% co-infection) } \\
\hline & & $\mathbf{1}$ & 2 & 3 & 4 & 5 \\
\hline \multicolumn{7}{|l|}{ Breed } \\
\hline Exotic & 1404 & $790(56.27)^{a, 1}$ & $448(31.91)^{b, 1}$ & $154(10.97)^{\mathrm{c}, 1}$ & $12(0.85)^{d, 1}$ & $0(0.00)^{e, 1}$ \\
\hline Cross & 553 & $400(72.33)^{a, 2}$ & $114(20.61)^{b, 2}$ & $35(6.33)^{c, 2}$ & $3(0.54)^{d, 1}$ & $1(0.18)^{d, 2}$ \\
\hline Indigenous & 863 & $494(57.24)^{\mathrm{a}, 1}$ & $239(27.69)^{b, 3}$ & $116(13.44)^{c, 1}$ & $12(1.39)^{d, 1}$ & $2(0.23)^{e, 2}$ \\
\hline \multicolumn{7}{|l|}{ Age } \\
\hline$<1$ years & 2038 & $1227(60.21)^{\mathrm{a}, 1}$ & $584(28.66)^{b, 1}$ & $208(10.21)^{\mathrm{c}, 1}$ & $16(0.79)^{d, 1}$ & $3(0.15)^{e, 1}$ \\
\hline 1-8years & 765 & $449(58.69)^{\mathrm{a}, 1}$ & $209(27.32)^{b, 1}$ & $96(12.55)^{\mathrm{c}, 1}$ & $11(1.44)^{d, 1}$ & $0(0.00)^{e, 2}$ \\
\hline$>8$ years & 17 & $8(47.06)^{a, 1}$ & $8(47.06)^{a, 1}$ & $1(5.88)^{b, 1}$ & $0(0.00)^{b, 2}$ & $0(0.00)^{b, 2}$ \\
\hline \multicolumn{7}{|l|}{ Gender } \\
\hline Male & 1375 & $823(59.85)^{a, 1}$ & $386(28.07)^{b, 1}$ & $152(11.05)^{c, 1}$ & $12(0.87)^{d, 1}$ & $2(0.15)^{e, 1}$ \\
\hline Female & 1445 & $861(59.58)^{a, 1}$ & $415(28.72)^{b, 1}$ & $153(10.59)^{c, 1}$ & $15(1.04)^{d, 1}$ & $1(0.07)^{e, 1}$ \\
\hline \multicolumn{7}{|l|}{ Season } \\
\hline Wet & 1674 & $982(58.66)^{a, 1}$ & $480(28.67)^{b, 1}$ & $188(11.23)^{\mathrm{c}, 1}$ & $21(1.25)^{d, 1}$ & $3(0.18)^{\mathrm{e}, 1}$ \\
\hline Dry & 1146 & $702(61.26)^{\mathrm{a}, 1}$ & $321(28.01)^{b, 1}$ & $117(10.21)^{c, 1}$ & $6(0.53)^{d, 2}$ & $0(0.00)^{e, 2}$ \\
\hline
\end{tabular}

Different alphabetical superscript $(\mathrm{a}, \mathrm{b}, \mathrm{c}, \mathrm{d}, \mathrm{e})$ indicate significant differences $(\mathrm{P}<0.05)$ across columns (of the same factor category). Different numbered superscripts $(1,2)$ indicate significant differences $(\mathrm{P}<0.05)$ across rows (of the same parasitic diseases co-infection category). 
Young dogs $(<1$ year old) and those between 1 and 8 years showed a significant $(P<0.05)$ decreased prevalence rate as the number of parasite(s) diagnosed increased. Eight $(47.06 \%)$ dogs in the age category of above 8 years were diagnosed with single and double parasitic disease conditions, while $5.88 \%$ was diagnosed with triple parasitic disease conditions. Within age groups, dogs above 8 years recorded a significantly lower prevalence of four parasites co-infection compared to dogs in the other age categories. Dogs below 1 year of age had a significantly higher prevalence of five parasites co-infection compared to the other age categories.

In terms of gender, the prevalence of infection decreased progressively and significantly $(P<0.05)$ as the number of parasitic disease coinfections increased. There was no significant difference between genders as it relates to the number of parasitic diseases co-infection.
The prevalence of parasitic disease condition decreased significantly $(P<0.05)$ as the number of co-infections increased as it relates to the two seasons considered. There was a higher prevalence of parasitic disease infection during the wet season compared to the dry season as it pertains to two, three, four and five parasitic diseases co-infection, the difference in the four and five parasites co-infection was significant, while that of two and three parasites coinfection category was not significant $(P>0.05)$.

The Spearman's correlation coefficient for parasitic diseases co-infection among dogs in Osun State (2006-2015) (Table 7) revealed there was a moderate and positive association between tick infestation and babesiosis, and between tick infestation and ehrlichiosis, this association was significant at $P<0.01$. The association between helminthosis and babesiosis, and helminthosis and tick infestation was significant at $P<0.01$, low and of a negative relationship.

Table 7. Spearman's correlation coefficient for parasitic diseases co-infection among dogs in Osun State (2006-2015).

\begin{tabular}{|c|c|c|c|c|c|c|c|c|c|}
\hline & Helminthosis & Babesiosis & $\begin{array}{l}\text { Ticks } \\
\text { Infestation }\end{array}$ & Myiasis & $\begin{array}{l}\text { Lice } \\
\text { Infestation }\end{array}$ & Mange & Ehrlichiosis & Flea Infestation & $\begin{array}{l}\text { Trypanosomosi } \\
\text { s }\end{array}$ \\
\hline Helminthosis & 1.000 & & & & & & & & \\
\hline Babesiosis & $-0.338^{* *}$ & 1.000 & & & & & & & \\
\hline Ticks Infestation & $-0.428^{* *}$ & $0.661^{* *}$ & 1.000 & & & & & & \\
\hline Myiasis & $-0.086^{* *}$ & $-0.048^{*}$ & $-0.077^{* *}$ & 1.000 & & & & & \\
\hline Lice Infestation & $-0.128^{* * *}$ & $-0.084^{* *}$ & $0.081^{* *}$ & -0.029 & 1.000 & 0.019 & -0.028 & & \\
\hline Mange & $-0.217^{* *}$ & $-0.093^{* *}$ & $-0.152^{* *}$ & -0.036 & 0.019 & 1.000 & 0.012 & & \\
\hline Ehrlichiosis & $-0.149^{* *}$ & $0.039^{*}$ & $0.539^{* *}$ & -0.012 & -0.028 & 0.012 & 1.000 & & \\
\hline Flea Infestation & -0.025 & -0.014 & 0.03 & -0.012 & $0.173^{* *}$ & 0.021 & -0.012 & 1.000 & \\
\hline Trypanosomosis & -0.037 & 0.026 & 0.004 & -0.007 & 0.007 & -0.02 & -0.007 & -0.007 & 1.000 \\
\hline
\end{tabular}

\footnotetext{
**. Correlation is significant at the 0.01 level (2-tailed).

*. Correlation is significant at the 0.05 level (2-tailed).
} 
A significant $(P<0.01)$ negligible and negative association was reported between helminthosis and myiasis, helminthosis and lice infestation, helminthosis and mange, helminthosis and ehrlichiosis, babesiosis and lice infestation, babesiosis and mange, tick infestation and myiasis, and tick infestation and mange. A similar strength but positive association was recorded in tick and lice infestations, and lice and flea infestations. A significant $(P<0.05)$ low and negligible association that is positive and negative was recorded among babesiosis and ehrlichiosis and babesiosis and myiasis respectively.

\section{DISCUSSION}

Parasitism exerts harmful and negative effects, and poses serious health challenges in domestic dogs (Canis lupus familiaris), such as reduced growth rate, generalized ill health, lowered resistance to infectious disease and reduced work efficiency [8]. Co-infection by multiple parasite species is a common occurrence and the normal state of animal's existence [3]. Helminthosis, babesiosis, ticks infestation, myiasis, lice infestation, mange, ehrlichiosis, flea infestation and trypanosomosis were the parasitic conditions reported among dogs in the study area. These parasitic disease conditions have been reported among dogs in Nigeria [9, 10, 16-19]. Helminthosis was the most single infection from our study. Helminthosis has been documented to be endemic among dogs in Nigeria $[8,20]$ and Bangladesh [21] .

The observed multiple parasitic disease conditions is supportive of the fact that co- infection of individual hosts by multiple parasites species is a pattern that is very commonly observed in populations [3]. Coinfections may cause parasites to either: (a) compete for host resources and overlapping ecological niches (exploitation competition) to continue replication (reproduction) and future survival (transmission), or (b) compete for parasite abundance to gain advantage in evading host immune capture (immunemediated apparent competition) [22].

The significant lower prevalence of five parasites co-infection recorded in the exotic breed of dogs compared to the indigenous and cross breeds is notable. In Nigeria, high prevalence of parasitic conditions has been reported in indigenous breed of dogs $[9,18,23]$ and their cross breeds [10]. Our findings may be attributed to the special care, good medical treatment, good housing and hygienic practice given to exotic breeds due to the cost of their purchase as only wealthy individuals keep exotic breeds of dogs. Also, the restricted access of exotic breeds to outdoor and controlled contact with other dogs and livestock may have favoured our findings.

Age has been reported to be a significant factor associated with the prevalence of canine parasitic disease in Nigeria [17, 23, 24], Africa [25] and other parts of the world [26, 27]. The high prevalence of five parasites co-infection seen in dogs less than 1 year old may be attributed to the tenderness of their skin, making 
it easier and more comforting for ectoparasites (e.g. ticks) to attach and transmit parasitic diseases. The underdevelopment of the immune system of young dogs may also contribute to the high prevalence of multiple parasitic infections recorded in our study.

Notably, there was no significant difference in the prevalence of parasitic diseases co-infection as it relates with gender. Adamu et al. [16] reported male dogs to be more susceptible to ectoparasitic, endoparasitic and haemoparasitic infections compared to female, and the difference was not significant. Okubanjo et al. [10] reported a non-significant higher prevalence of haemoparasitic infection in female dogs compared to male. Similarly, Opara et al. [28] reported that the occurrence of haemoprotozoan parasites among Nigerian local breed of dogs was not gender dependent.

The higher prevalence of parasitic diseases coinfection during the wet season could be attributed to the influence of higher level of rain fall and humidity which favors the breeding of arthropod vectors and the transmission of the parasitic diseases they are associated with. Mbaya et al. [29] reported a significantly higher prevalence of endoparasitic and ectoparasitic diseases in dogs during the wet season than the dry season.

The significant, moderate and positive association between tick infestation and babesiosis, and between tick infestation and ehrlichiosis is expected as ticks has been incriminated as the known vector responsible for the transmission of canine babesiosis and canine ehrlichiosis in Nigeria [10] and the world [30].

\section{Conclusion}

The findings of this study show that dogs in the study area were infected with multiple parasitic conditions. Also the occurrence of parasitic diseases co-infection in dogs in Osun State is breed, age and season dependent but not gender dependent. The occurrence of tick infestation with babesiosis, and tick infestation with ehrlichiosis was positively correlated. Multiple parasitic diseases co-infection could cause severe and adverse effect on the health, reproduction and performance of dogs in the study area. Therefore there is need for an improved Veterinary medical attention and hygienic practices given to dogs in the study area.

\section{Acknowledgement}

We would like to express our deep and sincere gratitude to the Director (Dr. Bukola Aluko) and all staff of the Department of Veterinary Services of Osun State for granting access to the record used for this study.

\section{REFERENCES}

1. Bordes, F. and Morand, S. (2011). The impact of multiple infections on wild animal hosts: a review. Infection Ecology and Epidemiology. 1: 7346-7355. 
2. Vaumourin, E., Vourc'h, G., Gasqui, P. and Vayssier-Taussat, M. (2015). The importance of multiparasitism: examining the consequences of coinfections for human and animal health. Parasites \& Vectors. 8: 545-557. DOI 10.1186/s13071-015-1167-9.

3. Viney, M.E. and Graham, A.L. (2013). Patterns and Processes in Parasite CoInfection.Advances in Parasitology, First Edition. 82: 321-369.

4. Lello, J., Boag, B., Fenton, A., Stevenson, I. and Hudson, P. (2004). Competition and mutualism among the gut helminths of a mammalian host. Nature. 428:840-844. (doi:10.1038/nature02490).

5. Thumbi, S. M., Bronsvoort, B.M.C., Poole, E.J., Kiara, H., Toye, P., Ndila, M., Conradie, I., Jennings, A., Handel, I.G., Coetzer, J.A.W., Hanotte, O. and Woolhouse, M.E.J. (2013). Parasite coinfections show synergistic and antagonistic interactions on growth performance of East African zebu cattle under one year. Parasitology. 140: 1789-1798.

6. Ugbomoiko, U.S., Ariza, L. and Heukelbach, J. (2008). Parasites of importance for human health in Nigerian dogs: high prevalence and limited knowledge of pet owners. $B M C$ Veterinary Research, 4: 49-57.

7. Tannen, D. (2004). Talking the dog: framing pets as interactional resources in family discourse. Research on Language and Social Interaction. 37: 399-420.

8. Tion, T.M., Ikurior, J.S. and Orbunde, K.D. (2016). The Prevalence of Gastrointestinal Helminths (GIH) Infection of Dogs in Makurdi Metropolis. Imperial Journal of Interdisciplinary Research. 2(8): 1042-1049.

9. Omudu, E. A., Okpe, G. and Adelusi, S. M. (2010). Studies on Dog Population in Makurdi, Nigeria (II): A Survey of Ectoparasite Infestation and Its Public
Health Implications. Journal of Research in Forestry, Wildlife and Environment. 2(1): 94-106.

10. Okubanjo, O. O., Adeshina, O. A., Jatau, I. D. and Natala, A. J. 2013. Prevalence of Babesia canis and Hepatozooncanis in Zaria. Nigeria. Sokoto Journal of Veterinary Sciences. 11(2): 15-20.

11. Sowemimo, O.A. and Ayanniyi, O.A. (2017). Gastrointestinal Helminth Parasites of Domestic Dogs in Ilesa, Osun State, Nigeria: A Faecal Examination Survey Study. Journal of Bacteriology and Parasitology. 8: 3-7.

12. National Bureau of Statistics (NBS) (2016). Annual abstract of statistics. Federal Republic of Nigeria. Pp. 5-10. Retrieved 2017 December 18 from http://www.nigerianstat.gov.ng/pdfupl oads/annual_abstract_2012.pdf.

13. Ola-Fadunsin, S.D. (2017). Retrospective occurrence and risk factors associated with cattle parasitic infections in Osun State, Nigeria. Nigerian Veterinary Journal 38(3): 195-209.

14. Soulsby, E.J.L. (1982). Helminths, arthropods and protozoan's of domesticated animals. BailliereTindall (7th ed), London. Pp. 471-474, 706-740.

15. Mukaka MM, 2012. Statistics corner: A guide to appropriate use of Correlation coefficient in medical research. Malawi Medical Journal. 24(3): 69-71.

16. Adamu, N.B., Adamu, J.Y. and Salisu, L. (2012). Prevalence of ecto-, endoand haemoparasites in slaughtered dogsin Maiduguri, Nigeria. Revue de MedecineVeterinaire. 163(4): 178-182.

17. Nonyelu, M.1. (2013). The Prevalence of Haemoparasitic Infection in Dogs Attending ECWA Vertinary Clinic, Bukuru, Jos South Local Government Area, Plateau State. Advances in Microbiology. 3: 302-308. 
18. Ogo, N.I., Onovoh, E., Ayodele, D.R., Ajayi, O.O., Chukwu, C.O., Sugun, M. and Okeke, I.O. (2009). Cutaneous canine myiasis in the Jos metropolis of Plateau State, Nigeria, associated with Cordylobia anthropophaga. Veterinary Arhiv. 79: 293-299.

19. Shima, K.F., Tion, T.M., Mosugu, I.J. and Apaa, T.T. (2015). Retrospective study of disease incidence and other clinical conditions diagnosed in owned dogs in Delta State, Nigeria.Journal of Advanced Veterinary and Animal Research.2(4): 435-449.

20. Odeniran, A.W., Aliyu, M.M., Nwosu, C.O., Ibrahim, U.I. and Shallaguwa, J.M. (2008). A ten-year retrospective study of the prevalence of parasitic infections of dogs at the University of Maiduguri Veterinary Teaching Hospital, Nigeria. NigerianVeterinary Journal.29(2):131-136.

21. Tarafder, M. and Samad, M.A. (2010). Prevalence of clinical diseases of pet dogs and risk perception of zoonotic infection by dog owners in Bangladesh. Bangladesh Journal of Veterinary Medicine.8(2):163-174.

22. Oakgrove, K.S., Harrigan, R.J., Loiseau, C., Guers, S., Seppi, B. and Sehgal, R.N.M. (2014). Distribution, diversity and drivers of blood-borne parasite co-infections in Alaskan bird populations. International Journal for Parasitology. 44: 717-727.

23. Akeredolu, A.B. and Sowemimo, O.A. (2014). Prevalence, intensity and associated risk factors for Toxocara canis infection in Nigerian dogs. Journal ofParasitology and Vector Biology.6(8):111-116.

24. Jegede, O.C., Obeta, S.S. and Faisal, B. (2014). Infection of dogs with Babesia canis in Gwagwalada area of Federal Capital Territory, Abuja, Nigeria. Sokoto Journal of Veterinary Sciences 12(3): 37-41.
25. Amissah-Reynolds, P.F., Monney, I., Adowah, L.M. and Agyemang, S.O. (2016). Prevalence of Helminths in Dogs and Owners' Awareness of Zoonotic Diseases in Mampong, Ashanti, Ghana. Journal of Parasitology Research. 6 pages. http://dx.doi.org/10.1155/2016/1715924.

26. Mahmud, M.A.A., Belal, S.M.S.H. and Uddin, F.M.J. (2014). Prevalence of Protozoan Diseases in Pet Dogs at District Veterinary Hospital, Sirajganj, Bangladesh. Bangladesh Journal of Veterinary Medicine. 12(2): 191-196.

27. Mosallanejad, B., Alborzi, A.R. and Katvandi, N. (2011). A Survey on Ectoparasite Infestations in Companion Dogs of Ahvaz District, South-west of Iran. Journal of Arthropod-Borne Diseases. 6(1): 70-78.

28. Opara, M.N., Adewumi, T.S., Mohammed, B.R., Obeta, S.S., Simon, M.K., Jegede, O.C. and Agbede, R.I.S. (2017). Investigations on the Haemoprotozoan Parasites of Nigerian Local Breed of Dogs in Gwagwalada Federal Capital Territory (FCT) Nigeria. Research Journal of Parasitology. 12(1): 1-7.

29. Mbaya, A.W., Aliyu, M., Nwosu, C.O., Ibrahim, U.I. and Shallanguwa, J.M. (2008). A ten-year retrospective study of the prevalence of parasite infections of dogs at the University of Maiduguri Veterinary Teaching Hospital, Nigeria. Nigeria Veterinary Journal. 29(2): 31-36.

30. Taylor, M.A., Coop, R.L. and Wall, R.L. (2007). Veterinary Parasitology, 3rd edition. Blackwell Publishing, Iowa State, USA, Pp. 409-426. 